\title{
Post-discharge mortality in patients with traumatic spinal cord injury in a Brazilian hospital: a retrospective cohort
}

\author{
Victor F. Leite $\mathbb{I}^{1} \cdot$ Daniel R. de Souza ${ }^{1,2} \cdot$ Marta Imamura $^{1} \cdot$ Linamara R. Battistella $^{1}$
}

Received: 24 February 2018 / Revised: 24 June 2018 / Accepted: 3 July 2018 / Published online: 8 August 2018

(c) International Spinal Cord Society 2018

\begin{abstract}
Study design Retrospective cohort.

Objective To evaluate the survival outcomes in patients with traumatic spinal cord injury (TSCI).

Setting A teaching hospital in Brazil.

Methods A total of 434 patients diagnosed with TSCI (2004-2014) were included. Overall survival, standardized mortality ratios (SMR), and causes of death were assessed by Student's $t$-test, $\chi^{2}$ test, Kaplan-Meier analysis, and Cox proportionalhazards regression.

Results The mean follow-up was 4.8 years ( \pm 3.3 years). Individuals with tetraplegia had a median survival of 11 years, with participants in the paraplegia group not reaching median survival. The overall mortality rate was 37 per 1000 person-years. Age-adjusted SMR was 28.8 (95\% CI: 22.8-36). There were 77 deaths with 56 defined causes, of which pneumonia was the most frequent $(35.7 \%)$. Combined infectious etiologies caused $55.3 \%$ of deaths. Multivariate analysis revealed higher mortality among individuals with tetraplegia vs. paraplegia in the first 2 years post injury (HR $=8.28,95 \% \mathrm{CI}: 2.76-24.80)$, after 2 years post injury $(\mathrm{HR}=2.35,95 \% \mathrm{CI}: 1.31-4.24)$, and in all years combined $(\mathrm{HR}=3.36,95 \% \mathrm{CI}: 2.04-5.52)$. Conclusion Mortality among patients with TSCI was 28.8 times higher than in the reference population. In more than half of the cases, the cause of death was linked to infectious diseases. Pneumonia caused two times more deaths in individuals with tetraplegia than in individuals with paraplegia, with a higher impact in the first 2 years post injury. Reported findings indicate the need for a surveillance and prevention program with emphasis on vaccination and respiratory rehabilitation.
\end{abstract}

\section{Introduction}

In low-income and middle-income countries (LMIC) [1], which account for $\sim 80 \%$ of the global population, epidemiological data on spinal cord injury (SCI) are particularly limited. Socioeconomic circumstances in LMIC often correlate with a higher incidence of traumatic SCI

Electronic supplementary material The online version of this article (https://doi.org/10.1038/s41393-018-0183-y) contains supplementary material, which is available to authorized users.

Victor F. Leite

victor@drvictorleite.com

1 Institute of Physical Medicine and Rehabilitation, Clinical Hospital of the Faculty of Medicine, University of São Paulo, Sao Paulo, Brazil

2 Institute of Orthopedics and Traumatology, Clinical Hospital of the Faculty of Medicine, University of São Paulo, Sao Paulo, Brazil
(TSCI), such as high rates of violence, road traffic injuries, and work-related accidents [1-6]. Current in-hospital survival estimates suggest that mortality in acute TSCI is approximately three times higher in LMIC than in highincome countries [7]. Post-discharge survival data in LMIC are scarce and heterogeneous. Although the data from South India show a 1-2-year mortality rate of $<5 \%$, the data from Bangladesh, Nepal, and Sierra Leone show rates of $13 \%, 25 \%$, and $61 \%$, respectively [8-11]. The most frequent causes of death, such as infections and pressure ulcers, were preventable [8, 10, 11]. When comparing individuals with TSCI in LMIC and highincome countries, there are many possible contributory factors for the disparity in mortality rates and etiologies, including limited access to healthcare for individuals with SCI, higher complication rates, and decreased social participation $[1,3,4,12]$. To the best of our knowledge, only two prior studies have investigated post-discharge mortality in large LMIC populations; both were conducted in Southern Asia [9, 10]. 
The metropolitan area of São Paulo, Brazil, has an estimated population of 20 million and unique socioeconomic characteristics. Obtaining the data on local mortality rates, risk factors, and causes of death for individuals with SCI would enable the development of preventive programs, and allow cost estimates and appropriate resource allocation by both local government and foreign aid organizations. Our study aimed to assess mortality rates and causes of death for people with TSCI who were admitted to a teaching hospital in São Paulo, Brazil between 2004 and 2014.

\section{Methods}

This article follows the Strengthening the Reporting of Observational Studies in Epidemiology (STROBE) initiative [13]. This retrospective hospital cohort study was approved by the Ethics Committee for Analysis of Research Projects (CAPPesq) of the Hospital das Clínicas at the University of São Paulo's Medical School, São Paulo, Brazil (CAPPesq CAAE:64907617.2.0000.0068).

Study design: Retrospective cohort.

Setting: Institute of Orthopedics and Traumatology (IOT), Clinical Hospital of the Faculty of Medicine, and University of São Paulo. The hospital is a quaternary public teaching facility with 2400 beds.

Study population: All cases of individuals with acute TSCI discharged alive are routinely included in the IOT data registry. Individuals discharged between January 2004 and December 2014 without age restriction were considered for inclusion $(n=454)$. Those with incomplete clinical data and/or unknown SCI date were excluded $(n=20)$. A total of 434 participants were included in the final analysis.

Data collection: Clinical history, demographic information, and outcomes were extracted from the hospital medical records. Data from all clinical encounters in our SCI clinic have been collected using the same standardized form since 2003. Enrolled participants were followed up until December 2016. Vital status updates were obtained from:

- Medical records from our hospital, including recent exams, and visits to other clinics;

- Telephone contacts with individuals and their families;

- City and State electronic databases for death certificates [14], which are managed by the City and by the State Health Department. After providing a list of identifiers for each individual, researchers obtained the corresponding death certificates.

Brazilian death certificates register the underlying cause of death, its consequent conditions, and the immediate cause of death, all coded by ICD-10. In this study, we defined the cause of death as the "underlying cause of death" noted in the death certificates. If chronic SCI was noted in death certificates as the underlying cause of death, we defined its first consequent condition as the cause of death for the purpose of this study.

Individuals with no hospital visit after 1 year and unknown vital status were considered lost to follow-up and were censored at the date of the last contact.

\section{Statistical analysis}

We conducted a survival analysis and analyzed the following parameters:

- Person-year incidence and median time to death;

- Standardized mortality ratios (SMR);

- Causes of mortality;

- Multivariate survival analysis.

Baseline demographics were analyzed by Student's $t$-test or $\chi^{2}$ test. The difference in survival between individuals with paraplegia and tetraplegia was assessed by Kaplan-Meier with log-rank statistics. Multivariate adjustment for confounding variables was performed using a Cox proportional hazards model. All covariates were established a priori: age, gender, time from injury to hospital admission, level of injury, American Spinal Injury Association Impairment Scale (AIS), spine surgery during admission, intra-hospital complications (deep vein thrombosis, orotracheal intubation, admission to the ICU, and pneumonia), time from injury to discharge, and mechanical ventilation at discharge. Covariate selection was made using a stepwise approach guided by the Bayesian information criterion with cumulative martingale residual plots and a Kolmogorovtype supremum test to evaluate the proportionality of hazards. There was no violation of the proportional hazards assumption. The standardized mortality ratio (SMR) was obtained relative to the reported mortality rates of the metropolitan city of São Paulo from 2004 to 2014 [14], using indirect standardization for age-specific rates. Causespecific SMRs were obtained relative to mortality rates by ICD-10 chapters. Confidence intervals of SMR were estimated using Fisher's exact test.

All analyses were performed using SAS version 9.4 (SAS Institute, Inc., Cary, NC, USA), and a nominal significance level of 0.05 was used in all testing.

\section{Results}

Baseline data and follow-up time are presented in Table 1. Overall mortality rate per 1000 person-years was 37; 35.8 in the first 2 years post injury and 25.4 for those that survived more than 2 years. Median survival for people with 
Table 1 Demographics, neurological data, and follow-up time

\begin{tabular}{|c|c|c|c|}
\hline & $\begin{array}{l}\text { Tetraplegia } \\
(n=186)\end{array}$ & $\begin{array}{l}\text { Paraplegia } \\
(n=248)\end{array}$ & $\begin{array}{l}\text { Total } \\
(n=434)\end{array}$ \\
\hline \multicolumn{4}{|c|}{ Age at injury, in years ${ }^{\dagger}$} \\
\hline Median (IQR) & $37(25-50)$ & $32(22-44)$ & $33(24-46)$ \\
\hline Mean (SD) & $38.9(16.5)$ & $33.3(15.1)$ & 35.7 (15.9) \\
\hline \multicolumn{4}{|l|}{ Gender } \\
\hline Male & $86.6 \%(161)$ & $83.1 \%(206)$ & $84.6 \%(367)$ \\
\hline Female & $13.4 \%(25)$ & $16.9 \%(42)$ & $15.4 \%(67)$ \\
\hline \multicolumn{4}{|l|}{ Neurologic level } \\
\hline $\mathrm{C} 1-\mathrm{C} 4$ & $33.9 \%(63)$ & - & $14.5 \%(63)$ \\
\hline AIS A & $20.9 \%(39)$ & - & $9 \%(39)$ \\
\hline AIS B & $5.4 \%(10)$ & - & $2.3 \%(10)$ \\
\hline AIS C & $3.7 \%(7)$ & - & $1.6 \%(7)$ \\
\hline AIS D & $3.2 \%(6)$ & - & $1.4 \%(6)$ \\
\hline Missing & $0.5 \%(1)$ & - & $0.2 \%(1)$ \\
\hline $\mathrm{C} 5-\mathrm{C} 8$ & $66.1 \%(123)$ & - & $28.3 \%(123)$ \\
\hline AIS A & $26.3 \%(49)$ & - & $11.2 \%(49)$ \\
\hline AIS B & $17.7 \%(33)$ & - & $7.6 \%(33)$ \\
\hline AIS C & $10.7 \%(20)$ & - & $4.6 \%(20)$ \\
\hline AIS D & $9.1 \%(17)$ & - & $3.9 \%(17)$ \\
\hline Missing & $2.2 \%(4)$ & - & $0.9 \%(4)$ \\
\hline T1-S5 & - & $100 \%(248)$ & $57.1 \%(248)$ \\
\hline AIS A & - & $61.3 \%(152)$ & $35 \%(152)$ \\
\hline AIS B & - & $13.7 \%(34)$ & $7.8 \%(34)$ \\
\hline AIS C & - & $11.3 \%(28)$ & $6.4 \%(28)$ \\
\hline AIS D & - & $6.5 \%(16)$ & $3.7 \%(16)$ \\
\hline Missing & - & $6.8 \%(17)$ & $3.9 \%(17)$ \\
\hline $\begin{array}{l}\text { Mechanical } \\
\text { ventilation at } \\
\text { discharge }\end{array}$ & $1.1 \%(2)$ & $2 \%(5)$ & $1.6 \%(7)$ \\
\hline \multicolumn{4}{|l|}{ Cause of $\mathrm{TSCI}^{\dagger}$} \\
\hline Falls & $40.3 \%(75)$ & $43.6 \%(108)$ & $42.2 \%(183)$ \\
\hline Traffic injuries & $38.2 \%(71)$ & $35.1 \%(87)$ & $36.4 \%(158)$ \\
\hline Assault & $7.5 \%(14)$ & $13.3 \%(33)$ & $10.8 \%(47)$ \\
\hline Sports/leisure & $11.8 \%(22)$ & $0.8 \%(2)$ & $5.5 \%(24)$ \\
\hline Fall of object & $2.2 \%(4)$ & $6 \%(15)$ & $4.4 \%(19)$ \\
\hline Others & - & $1.2 \%(3)$ & $0.7 \%$ \\
\hline \multicolumn{4}{|c|}{ Length of hospital stay, days } \\
\hline Median (IQR) & $45(26-80)$ & $41.5(29-65)$ & $43(28-72)$ \\
\hline Mean (SD) & $65.1(64.1)$ & $55.4(47.4)$ & $59.6(55.3)$ \\
\hline \multicolumn{4}{|c|}{ Follow-up time, years } \\
\hline Mean (SD) & $4.4(3.2)$ & $5.1(3.4)$ & $4.8(3.3)$ \\
\hline Median (IQR) & $3.8(1.5-7.1)$ & $4.3(2.2-8.3)$ & $4.1(1.8-7.8)$ \\
\hline
\end{tabular}

${ }^{\dagger} p<0.05$ comparing tetraplegia and paraplegia

tetraplegia was 11 years. Median survival for people with paraplegia and for the overall cohort was not reached. Individuals with tetraplegia had higher mortality than those with paraplegia (Fig. 1).

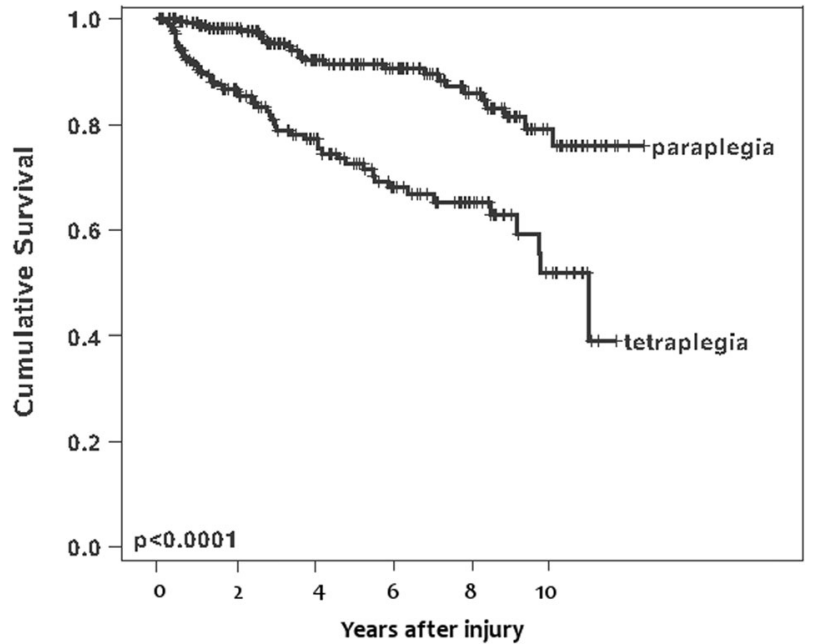

Fig. 1 Survival after spinal cord injury by injury level

There were 77 deaths (Table 2), of which 29 occurred in the first 2 years post injury. Considering all causes of death, multivariate analysis showed that people with tetraplegia had higher mortality than those with paraplegia (Table 3). Cox regression according to time post injury showed that the effect of tetraplegia on mortality was higher when analyzing only the first 2 years post injury ( $\mathrm{HR}=8.28,95 \%$ CI: $2.76-24.80, p=0.0002$ ), compared with the analysis of more than 2 years post injury $(\mathrm{HR}=2.35,95 \% \mathrm{CI}$ : $1.31-4.24, p=0.0042$ ). Further details of the Cox regression by time post injury can be found in Table S1.

Compared to the population of São Paulo, our cohort presented a SMR $=28.8$ (Table 4). Defined causes of death were available in 56 cases (Table 5). Pneumonia was the most frequent cause $(35.7 \%)$, and combined infectious etiologies caused $55.3 \%$ of deaths. Cancer, which was the cause of death in four individuals, occurred in the following primary sites: colorectal, testicular, head/neck, and unknown primary. A comprehensive list of the causes of death stratified by time post injury ( $<2$ vs. $\geq 2$ years) can be found in Table $\mathrm{S} 2$.

\section{Discussion}

To the best of our knowledge, this is the first study evaluating post-discharge mortality of people with SCI in Brazil. Our cohort exhibited a high mortality rate, which was more pronounced in the first 2 years post injury. Higher mortality in the acute period after SCI also has been observed in several other studies [14-18].

Pneumonia caused high number of deaths, namely $35.7 \%$ of total defined cases, with a higher impact in the group 
with tetraplegia. Although this is not uncommon for individuals with SCI [19-25], the proportion of deaths attributed to pneumonia was higher in this cohort than in other populations $[18-20,26,27]$. Here, we present several

Table 2 Deceased status, in percentage (frequency), by different characteristics

\begin{tabular}{llll}
\hline & Deceased & & \\
\cline { 2 - 4 } & Yes $(n=77)$ & No $(n=226)$ & $\begin{array}{l}\text { Unknown } \\
(n=131)\end{array}$ \\
\hline Gender & & & \\
Male & $89.6 \%(69)$ & $84.1 \%(190)$ & $82.5 \%(108)$ \\
Female & $10.4 \%(8)$ & $15.9 \%(36)$ & $17.6 \%(23)$ \\
Age at end of study & & & \\
$<15$ & $0 \%(0)$ & $3.5 \%(8)$ & $3.1 \%(4)$ \\
$15-29$ & $14.3 \%(11)$ & $23.5 \%(53)$ & $37.4 \%(49)$ \\
$30-44$ & $31.2 \%(24)$ & $35.4 \%(80)$ & $32.8 \%(43)$ \\
$45-59$ & $27.3 \%(21)$ & $27.9 \%(63)$ & $20.6 \%(27)$ \\
$60-74$ & $19.5 \%(15)$ & $8.9 \%(20)$ & $4.6 \%(6)$ \\
$>75$ & $7.8 \%(6)$ & $0.9 \%(2)$ & $1.5 \%(2)$ \\
Neurological level & & & \\
C1-C4 & $32.5 \%(25)$ & $9.3 \%(21)$ & $13 \%(17)$ \\
Complete & $22.1 \%(17)$ & $5.8 \%(13)$ & $6.9 \%(9)$ \\
Incomplete & $10.4 \%(8)$ & $3.5 \%(8)$ & $5.3 \%(7)$ \\
C5-C8 & $35.1 \%(27)$ & $26.1 \%(59)$ & $28.2 \%(37)$ \\
Complete & $22 \%(17)$ & $8.4 \%(19)$ & $9.9 \%(13)$ \\
Incomplete & $9.1 \%(7)$ & $17.7 \%(40)$ & $17.6 \%(23)$ \\
T1-S5 & $32.5 \%(25)$ & $64.6 \%(146)$ & $58.8 \%(77)$ \\
Complete & $23.4 \%(18)$ & $42.5 \%(96)$ & $29 \%(38)$ \\
Incomplete & $9.1 \%(7)$ & $16.8 \%(38)$ & $26 \%(34)$ \\
\hline & & &
\end{tabular}

potential explanations for this outcome, although more studies would be needed to draw firm conclusions. First, since no death certificate reported an influenza-related death, it is likely that some influenza cases were miscoded as pneumonia. Miscoding other pulmonary infections as pneumonia is, unfortunately, a common mistake in death certificates in Brazil [28, 29]. Second, respiratory rehabilitation was not part of the standard treatment for individuals with SCI in the outpatient setting. It is possible that our participants had a sub-optimal respiratory capacity and, therefore, had an increased risk for pneumonia [23-25, 30, 31].

Urogenital diseases caused $10.7 \%$ of defined deaths, all due to urinary tract infections. They presented the second highest cause-specific SMR in this cohort. Management of neurogenic bladder in our population has several limitations, such as: obtaining proper equipment/material for catheterization, difficulty in obtaining anticholinergic medication, and deviations in the catheterization technique [32].

All deaths attributed to skin diseases were due to pressure ulcers. They caused $7.1 \%$ of defined deaths and the highest cause-specific SMR. Preventing pressure ulcers can be very challenging in our population, since there is a high prevalence of poor social and family, which hinders the compliance to frequent postural shift. Since those individuals usually live in regions with poor accessibility and low availability of wound care centers, treatment is also a challenge.

Cancer was the most common cause of mortality in individuals with paraplegia, followed by pneumonia. However, due to the small number of these cases, it is difficult to establish an association between paraplegia and cancer-related deaths. Only one out of four cancer cases was
Table 3 Univariable and multivariable regression for mortality risk

\begin{tabular}{|c|c|c|c|c|c|c|}
\hline \multirow[b]{2}{*}{ Variables } & \multicolumn{3}{|c|}{ Univariable analysis } & \multicolumn{3}{|c|}{ Multivariable analysis } \\
\hline & HR & $95 \% \mathrm{CI}$ & $P$ & HR & $95 \% \mathrm{CI}$ & $P$ \\
\hline Age at injury $($ years $)=1$ & 1.04 & 1.03-1.16 & $<0.001$ & 1.05 & 1.03-1.06 & $<0.001$ \\
\hline Age at injury $(>65)=1$ & 4.07 & 2.21-7.49 & $<0.001$ & & & \\
\hline Complete injury & 2.15 & 1.30-3.57 & 0.003 & 2.71 & $1.61-4.54$ & $<0.001$ \\
\hline DVT $($ yes $)=1$ & 0.62 & $0.23-1.71$ & 0.359 & & & \\
\hline ICU admission (yes) $=1$ & 2.41 & 1.48-3.92 & $<0.001$ & & & \\
\hline Intubation during acute period (yes) $=1$ & 2.43 & 1.49-3.96 & $<0.001$ & & & \\
\hline Male $($ yes $)=1$ & 1.44 & $0.69-3.01$ & 0.335 & & & \\
\hline Mechanical ventilation at discharge (yes) $=1$ & 0.89 & $0.12-6.45$ & 0.911 & & & \\
\hline Pneumonia (yes) $=1$ & 1.21 & $0.73-2.03$ & 0.453 & & & \\
\hline Spasticity $($ yes $)=1$ & 0.89 & $0.53-1.51$ & 0.671 & & & \\
\hline Tetraplegia (yes) $=1$ & 3.25 & $2.01-5.24$ & $<0.001$ & 3.36 & $2.04-5.52$ & $<0.001$ \\
\hline Time from injury to discharge (days) & 1.00 & $1.00-1.00$ & 0.220 & & & \\
\hline Tracheostomy at discharge (yes) $=1$ & 1.12 & $0.50-2.82$ & 0.802 & & & \\
\hline UTI during acute period (yes) $=1$ & 1.93 & $1.09-3.42$ & 0.024 & & & \\
\hline
\end{tabular}

$D V T$ deep vein thrombosis, ICU intensive care unit, $U T I$ urinary tract infection

Bold values highlight the statistically significant results 
Table 4 Standardized mortality ratios (SMR), per age

\begin{tabular}{lllll}
\hline Age & Deaths & $\begin{array}{l}\text { Expected } \\
\text { deaths }\end{array}$ & $\begin{array}{l}\text { Years of } \\
\text { exposure }\end{array}$ & SMR (95\% CI) \\
\hline$<2$ & \multicolumn{3}{c}{ years after injury } \\
$<15$ & 0 & 0.01 & 20.7 & - \\
$15-29$ & 3 & 0.13 & 194.5 & $22.9(4.8-67.4)$ \\
$30-44$ & 8 & 0.30 & 261.3 & $26.5(11.5-52.6)$ \\
$45-59$ & 10 & 0.70 & 192.2 & $14.2(6.9-26.3)$ \\
$60-74$ & 6 & 0.77 & 67.5 & $7.8(2.9-17)$ \\
$>75$ & 2 & 0.77 & 17.7 & $2.6(0.3-9.4)$ \\
Total & 29 & 2.67 & 754.1 & $10.8(7.3-15.6)$ \\
$\geq 2$ years & after injury & & \\
$<15$ & 0 & 0.01 & 23.2 & - \\
$15-29$ & 8 & 0.09 & 254.2 & $89.6(38.4-175.1)$ \\
$30-44$ & 16 & 0.24 & 550.5 & $67.2(38.1-108.3)$ \\
$45-59$ & 11 & 0.53 & 359.8 & $20.6(10.4-37.1)$ \\
$60-74$ & 9 & 0.53 & 110.5 & $17.1(7.8-32.2)$ \\
$>75$ & 4 & 0.54 & 28.7 & $7.5(2-19)$ \\
Total & 48 & 1.98 & 1327 & $24.2(17.9-32.1)$ \\
All years & & & \\
$<15$ & 0 & 0.01 & 44 & $-19.5(10.9-32.1)$ \\
$15-29$ & 11 & 0.13 & 448.7 & $76.3(42.2-151.4)$ \\
$30-44$ & 24 & 0.30 & 811.9 & $83(51.3-119)$ \\
$45-59$ & 21 & 0.70 & 552 & $29.8(18.6-45.9)$ \\
$60-74$ & 15 & 0.77 & 178.1 & $19.5)$ \\
$>75$ & 6 & 0.77 & 46.4 & $7.8(22.8-36)$ \\
Total & 77 & 2.67 & 2081.1 & 28.8 \\
\hline
\end{tabular}

diagnosed in a primary site that has a well-established screening protocol.

Considering the frequency of each cause of death, their respective SMRs, and potential impact of interventions, we should aim in reducing the incidence of respiratory infections. The emphasis on adherence to pneumonia and influenza vaccination during follow-up appointments, both of which are covered by the Brazilian government for individuals with SCI, represents a readily implementable change that may be highly beneficial. In Brazil, Streptococcus pneumoniae and influenza viruses are the most frequent causes of bacterial and viral pneumonia, respectively [3335]. We also suggest the development of respiratory rehabilitation guidelines focused on prevention of respiratory complications [30, 36]. New research should be conducted on the impact of such activities on patient mortality.

Prevention of pressure ulcers can be challenging in settings with low resources, but the evidence to support the efficacy of specific strategies is lacking. Data from Bangladesh and Pakistan suggest that education and regular phone contact are feasible strategies for its prevention, although with unclear efficacy $[37,38]$.

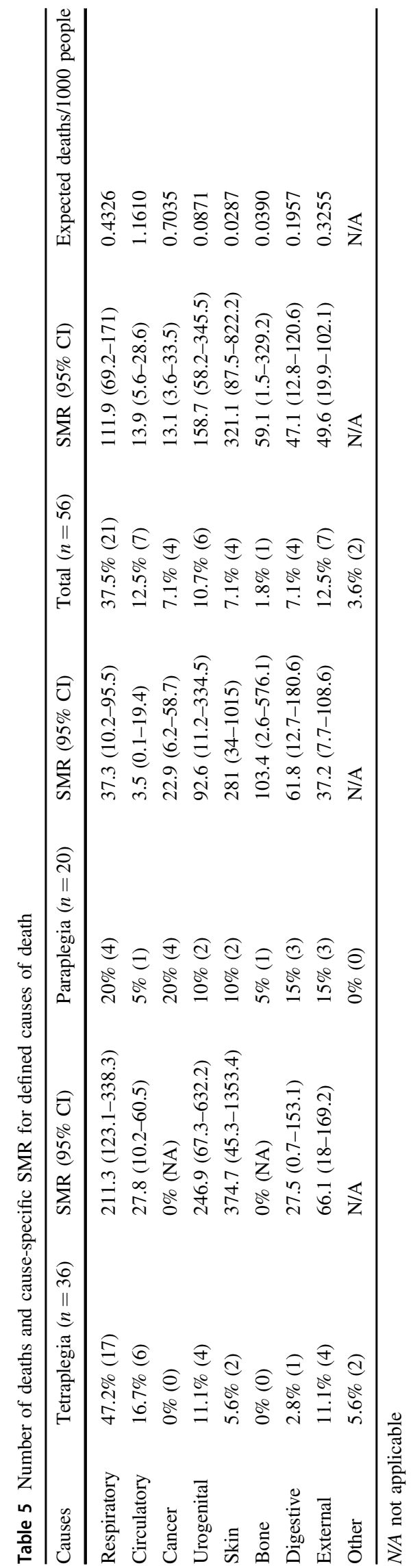




\section{Study limitations}

The present study has several limitations. First, $30.2 \%$ of the cohort had unknown deceased status. Even though the data were extracted from a metropolitan mortality database, this database only provides information on instances when the individual is deceased; if the person is alive, the database is defined as unknown. Secondly, $27.3 \%$ of mortality causes were unknown, primarily due to poorly reported death certificates, an unfortunately common problem in Brazil [39-41]. Hence, it is possible that the ranking of causes presented is inaccurate. Thirdly, the generalizability of our results might be limited, since our study was conducted in a national reference center for SCI located in the largest city in Brazil. It is likely that patients treated in centers with less experience, resources, and training will have different outcomes.

\section{Conclusion}

Our cohort presented high rates of death by preventable causes. The care of individuals with SCI in our center should emphasize the prevention of such causes. Focusing on vaccination and respiratory rehabilitation seems a readily implementable way to improve SCI outcomes in this population.

Author contributions VFL was responsible for the study design, data collection, data interpretation, manuscript writing, and manuscript editing. DRS was responsible for data collection, data interpretation, and manuscript editing. MI was responsible for study design and manuscript editing. LRB was responsible for the study design, data interpretation, and manuscript editing.

\section{Compliance with ethical standards}

Conflict of Interest The authors declare that they have no conflict of interest.

\section{References}

1. World Health Organization. WHO: International Perspectives on Spinal Cord Injury. Geneva: WHO; 2013.

2. Rahimi-Movaghar V, Sayyah MK, Akbari H, Khorramirouz R, Rasouli MR, Moradi-Lakeh M, et al. Epidemiology of traumatic spinal cord injury in developing countries: a systematic review. Neuroepidemiology. 2013;41:65-85.

3. Lofvenmark I, Wikmar LN, Hasselberg M, Norrbrink C, Hultling C. Outcomes 2 years after traumatic spinal cord injury in Botswana: a follow-up study. Spinal Cord. 2017;55:285-9.

4. Munakomi S, Bhattarai B, Cherian I. Prospective observational research on the clinical profile and outcome analysis among a cohort of patients sustaining traumatic cervical spine and cord injury in a peripheral tertiary spine care centre in Nepal. F1000Res. 2017;6:1957.

5. Hagen EM. Still a need for data from developing countries on traumatic spinal cord injury. Neuroepidemiology. 2013;41:86-7.
6. Burns AS, O'Connell C. The challenge of spinal cord injury care in the developing world. J Spinal Cord Med. 2012;35:3-8.

7. Chamberlain JD, Meier S, Mader L, von Groote PM, Brinkhof MWG. Mortality and longevity after a spinal cord injury: systematic review and meta-analysis. Neuroepidemiology. 2015;44:182-98.

8. Scovil CY, Ranabhat MK, Craighead IB, Wee J. Follow-up study of spinal cord injured patients after discharge from inpatient rehabilitation in Nepal in 2007. Spinal Cord. 2012;50:232-7.

9. Barman A, Shanmugasundaram D, Bhide R, Viswanathan A, Magimairaj HP, Nagarajan G, et al. Survival in persons with traumatic spinal cord injury receiving structured follow-up in South India. Arch Phys Med Rehabil. 2014;95:642-8.

10. Hossain MS, Rahman MA, Herbert RD, Quadir MM, Bowden JL, Harvey LA. Two-year survival following discharge from hospital after spinal cord injury in Bangladesh. Spinal Cord. 2016;54:132-6.

11. Gosselin RA, Coppotelli C. A follow-up study of patients with spinal cord injury in Sierra Leone. Int Orthop. 2005;29:330-2.

12. Rashid SM, Jusabani MA, Mandari FN, Dekker MCJ. The characteristics of traumatic spinal cord injuries at a referral hospital in Northern Tanzania. Spinal Cord Ser Cases. 2017;3:17021.

13. von Elm E, Altman DG, Egger M, Pocock SJ, Gøtzsche PC, Vandenbroucke JP. The strengthening the reporting of observational studies in epidemiology (STROBE) statement: guidelines for reporting observational studies. Lancet. 2007;370:1453-7.

14. Prefeitura de São Paulo. Programa de Aprimoramento das Informações de Mortalidade no Município de São Paulo (PRO-AIM). Sistema de Informações sobre Mortalidade (SIM).

15. Yeo JD, Walsh J, Rutkowski S, Soden R, Craven M, Middleton J. Mortality following spinal cord injury. Spinal Cord. 1998;36:329-36.

16. Strauss DJ, Devivo MJ, Paculdo DR, Shavelle RM. Trends in life expectancy after spinal cord injury. Arch Phys Med Rehabil. 2006;87:1079-85.

17. Savic G, DeVivo MJ, Frankel HL, Jamous MA, Soni BM, Charlifue S. Causes of death after traumatic spinal cord injury-a 70-year British study. Spinal Cord. 2017;55:891-7.

18. Sabre L, Rekand T, Asser T, Korv J. Mortality and causes of death after traumatic spinal cord injury in Estonia. J Spinal Cord Med. 2013;36:687-94.

19. Cao Y, Selassie AW, Krause JS. Risk of death after hospital discharge with traumatic spinal cord injury: a population-based analysis, 1998-2009. Arch Phys Med Rehabil. 2013;94:1054-61.

20. Lidal IB, Snekkevik H, Aamodt G, Hjeltnes N, Biering-Sorensen F, Stanghelle JK. Mortality after spinal cord injury in Norway. J Rehabil Med. 2007;39:145-51.

21. Brommer B,Engel O,Kopp MA,Watzlawick R,Muller S,Pruss H, et al. Spinal cord injury-induced immune deficiency syndrome enhances infection susceptibility dependent on lesion level. Brain. 2016;139(Pt 1):692-707.

22. Kanyilmaz S, Hepguler S, Atamaz FC, Gokmen NM, Ardeniz O, Sin A. Phagocytic and oxidative burst activity of neutrophils in patients with spinal cord injury. Arch Phys Med Rehabil. 2013;94:369-74.

23. Raab AM, Krebs J, Perret C, Michel F, Hopman MT, Mueller G. Maximum inspiratory pressure is a discriminator of pneumonia in individuals with spinal-cord injury. Respir Care. 2016;61:1636-43.

24. Brown R, DiMarco AF, Hoit JD, Garshick E. Respiratory dysfunction and management in spinal cord injury. Respir Care. 2006;51:853-68.

25. Berlowitz DJ, Wadsworth B, Ross J. Respiratory problems and management in people with spinal cord injury. Breathe. 2016;12:328-40. 
26. Middleton JW, Dayton A, Walsh J, Rutkowski SB, Leong G, Duong S. Life expectancy after spinal cord injury: a 50-year study. Spinal Cord. 2012;50:803-11.

27. Ahoniemi E, Pohjolainen T, Kautiainen H. Survival after spinal cord injury in Finland. J Rehabil Med. 2011;43:481-5.

28. Franca E, Teixeira R, Ishitani L, Duncan BB, Cortez-Escalante JJ, Morais Neto OL, et al. Ill-defined causes of death in Brazil: a redistribution method based on the investigation of such causes. Rev Saude Publica. 2014;48:671-81.

29. Cardoso BB, Kale PL. Coding pulmonary sepsis and mortality statistics in Rio de Janeiro, RJ. Rev Bras Epidemiol. 2016;19:609-20.

30. Tamplin J, Berlowitz DJ. A systematic review and meta-analysis of the effects of respiratory muscle training on pulmonary function in tetraplegia. Spinal Cord. 2014;52:175-80.

31. Postma K, Bussmann JB, Haisma JA, van der Woude LH, Bergen MP, Stam HJ. Predicting respiratory infection one year after inpatient rehabilitation with pulmonary function measured at discharge in persons with spinal cord injury. J Rehabil Med. 2009;41:729-33.

32. Lopes MA, Lima ED. Continuous use of intermittent bladder catheterization-can social support contribute? Rev Lat Am Enferm. 2014;22:461-6.

33. Raboni SM, Moura FEA, Caetano BC, Avanzi VM, Pereira LA, Nogueira MB, et al. Global Influenza Hospital-based Surveillance Network (GIHSN): results of surveillance of influenza and other respiratory viruses in hospitalised patients in Brazil, 2015. BMJ Open. 2018;8:e017603.

34. Correa AR, Lundgren FL, Pereira-Silva JL, Frare e Silva RL, Cardoso AP, Lemos AC, et al. Brazilian guidelines for community-acquired pneumonia in immunocompetent adults2009. J Bras Pneumol. 2009;35:574-601.

35. Donalisio MR, Arca CHM, Madureira PRd. Perfil clínico, epidemiológico e etiológico de pacientes com pneumonia adquirida na comunidade internados em um hospital geral da microrregião de Sumaré, SP. J Bras Pneumol. 2011;37:200-8.

36. Teeter L, Gassaway J, Taylor S, LaBarbera J, McDowell S, Backus D, et al. Relationship of physical therapy inpatient rehabilitation interventions and patient characteristics to outcomes following spinal cord injury: the SCIRehab project. J Spinal Cord Med. 2012;35:503-26.

37. Hossain MS, Harvey LA, Rahman MA, Bowden JL, Islam MS, Taylor V, et al. A pilot randomised trial of community-based care following discharge from hospital with a recent spinal cord injury in Bangladesh. Clin Rehab. 2017;31:781-9.

38. Chishtie J, Chishtie F, Yoshida K, Balogh R. Spinal cord injury rehabilitation and pressure ulcer prevention after the 2005 South Asian Earthquake: a CBR case study from Pakistan. Disabil Rehabil. 2018;1-9.

39. Mendonça FM, Drumond E, Cardoso AMP. Problemas no preenchimento da Declaração de Óbito: estudo exploratório. Rev Bras Estud Popul. 2010;27:285-95.

40. Messias KLM, Bispo Júnior JP, Pegado MFdQ, Oliveira LC, Peixoto TG, Sales MAC, et al. Qualidade da informação dos óbitos por causas externas em Fortaleza, Ceará, Brasil. Cien Saude Colet. 2016;21:1255-67.

41. Silva JACd, Yamaki VN, Oliveira JPSd, Teixeira RKC, Santos FAF, Hosoume VSN. Declaração de óbito, compromisso no preenchimento. Avaliação em Belém-Pará, em 2010. Rev Assoc Med Bras. 2013;59:335-40. 